\title{
REQUIREMENTS IDENTIFICATION FOR A PDP REFERENCE MODEL FOR MEDICAL DEVICES
}

Karyn Martinelli Lopes (kmlopes@ usp.br) - Department of Production Engineering of the Polytechnic School, University of São Paulo.

Eduardo de Senzi Zancul (ezancul@usp.br) - Department of Production Engineering of the Polytechnic School, University of São Paulo.

\begin{abstract}
The aim of the article is to present the requirements for a PDP reference model for medical devices. The methodological approach selected is a case study of six medical devices projects, carried out at the research group in which this article is inserted. The results of theoretical and empirical research show the initial requirements and the importance of regulatory issues. The projects analyzed employed the Biodesign approach. However, it is still necessary to improve the research about the requirements and medical devices development in Brazil. This article is part of a broader research that aims to develop a specific PDP reference model for the health sector.
\end{abstract}

Keywords: PDP reference model; Medical devices; Biodesign

Area: Process models for products and services development

\section{INTRODUCTION}

Brazil is a country of continental dimensions with widespread regional and social inequalities. Brazilian health sector consists of a variety of public and private organizations (PAIM et al., 2011) and it is still an area that presents opportunities for the product development process (PDP). Such opportunities come from a number of factors, such as the high public health expenditures in the country involving a significant volume of government purchases, excellence in health treatment of some medical centers in the country (ITA, 2016), population's increasing life expectancy (WHO, 2014), and the need for low cost alternative solutions. High quality but lower technology medical device firms are being challenged by numerous lower-cost producers from Brazil (ZAPIAIN, 2016).

As a consequence, the need for medical technologies that deliver clear value to their intended users has never been more imperative. In developing countries, such as Brazil, patients are demanding increased access to more advanced healthcare (YOCK et al, 2015). Brazilian health system is made up of a complex network of complementary and competitive service providers and purchasers (PAIM et al., 2011).

Health systems in developing countries recognize they are facing increased demand for medical technologies but are actively pursuing more affordable, cost effective products and 
services designed specifically to address the needs of patients and providers in settings with fewer resources (YOCK et al., 2015). In recent years, the number of publications regarding product development approaches has increased. However, few are dedicated to medical devices (SANTOS et al., 2011). In order to exploit these opportunities, there is a need to systematize the product development for the health area, since this development involves distinct activities at various stages of the PDP.

Thus, the aim of this article is to present the requirements for a PDP reference model for medical devices. This article is part of an extensive research that aims to develop a specific PDP reference model for the health sector.

The remnant of the article is structured as follows. The next two sections describe the literature review on specific and medical device reference models, including their aspects and requirements. Afterward, the article presents a case study of medical devices projects carried out at the research group in which this article is inserted. Finally, the results and conclusions sections dissert the findings and opportunities for further research.

\section{SPECIFIC REFERENCE MODELS}

Reference models are information models that are developed with the goal of being reused for different, but similar purposes. The benefit of using reference models is predominantly the reduction of development costs, due to the possible reuse of knowledge (BECKER;

DELFMANN, 2007). There are several reference models in the most varied sectors, such as automotive and aircraft. Some of them can be summarized as follows.

Silva and Kaminski (2017) developed a complete framework for managing the automotive PDP. The main advantage of this framework is to access a generic automotive reference model that contains a complete set to manage this process. The reference model is based on the theoretical reference on PDP modeling and examples of automotive PDP. The model consists of three macro-phases: product strategy, product development and production and continuous improvement. The macro-phase of product strategy is characterized by the start of the automobile development. In the macro-phase of product and process development, there is the development of the product and the means required for its production. Product development occurs in parallel to the development process. In the macro-phase of production and continuous improvement, there is the follow-up of the production and the identification of possible improvements in the product and in the manufacturing process. The expected results are: a larger interaction among the professionals involved, work standardization and therefore reduction of wastes. A consequent reduction in costs and investments by the organizations can also be expected.

Ryberg, Bäckryd and Nilsson (2015) presented a process for multidisciplinary design optimization (MDO) for large-scale automotive structural applications where different groups need to work concurrently and autonomously using computationally expensive simulation models. The steps are: define problem (load cases, objectives, constraints, and design variables); find important design variables; define design of experiments, run simulations, and extract results; build, check, and compare meta-models; find optimum solutions and check results with detailed model. The requirements identified on the MDO process for large scale automotive structural applications with computationally expensive simulation models can be: the groups need to work concurrently and autonomously; the process must be able to incorporate meta-models; the process must be flexible and able to handle multiple objectives and robustness considerations. 
The product development unified model, developed by Rozenfeld et al. (2006), has similarity with Design for Six Sigma (DFSS), Maturity Models and Product Lifecycle Management. It considers comparisons and evaluations carried out from leading companies PDP reference models and focuses on mechanical manufacturing technology, oriented to durable consumer goods sector, such as device production, appliances, white goods (refrigerator, stove, and washing machine), automobiles etc. The model has three macro-phases, subdivided into phases and activities: pre-development, development and post-development. Pre- and postdevelopment macro-phases are more generic and can be used in other types of companies with minor changes. The development macro-phase emphasizes the technological aspects corresponding to the product definition itself, its characteristics and production form. Therefore, such activities are dependent on the technology involved in the product. The phases are constituted by: project planning, informational project, conceptual project, detailed project, preparation, production and product launch. The model applies requirements related to aspects such as: functional performance (desired behavior for the product, terms of energy flows, material and signal, or for information about the operations and their sequence); human factors (product interface with people), properties (physical, electrical, thermal, mechanical, chemical and nuclear properties); space, product reliability (consequences of failure and safety), product life cycle (considers the different aspects of the phases through which the product will pass, in addition to those related to the phase of use), resources (time, capital costs and manufacturing). Costs involve product impact during production, use and withdrawal.

In conclusion, reference models are generated from requirements derived from approaches, researches and practices. However, as Becker and Delfmann (2007) observed, adaptations are necessary since the reference model has to comply with the particular application context. Application contexts depend on company specifics on the one hand and requirements of different user groups within a company on the other hand. In order to comply with particular application contexts, reference models are either to be aligned to a specific user group or need to comprise concepts that facilitate an easy and efficient adaptation process.

\section{MEDICAL DEVICE REFERENCE MODELS}

New product ideas are not simply born and come from examining the needs of hospitals, nurses, respiratory therapists, physicians, and other medical professionals, as well as from sales and marketing personnel. These problems generally represent product opportunities (FRIES, 2013). Medical technology has seen rapid and far-reaching advances in recent decades. However, the development and adoption of most technological innovations have been limited to the industrialized world. Furthermore, advanced technology is frequently defined based on a paradigm that considers advancement synonymous with increased digitization and optimization of electronic processes (FATUNDE; BHATIA, 2012).

In relation to medical device, Fries (2006) defines "as any instrument, appliance, apparatus, material or other article, whether used alone or in combination, including the software necessary for its proper application, intended by the manufacturer to be used for human beings for the purpose of: diagnosis, prevention, monitoring, treatment or alleviation of disease; diagnosis, monitoring, alleviation of or compensation for an injury or handicap investigation, replacement or modification of the anatomy or of a physiological process; control of conception and which does not achieve its principal intended action in or on the human body by pharmacological, immunological, or metabolic means, but which may be assisted in its function by such means". 
Although the purpose of medical devices is to help solve health problems, not all medical devices are confirmed to be safe for use at the beginning of a design stage. In other words, the benefits of the new device must outweigh the risks brought about by the device to the patient; this is the evaluation standard used before marketing a device. Safe devices must be constructed from safe raw materials. The composition of the materials that make up the device should be clear as any potential leaching materials would present a hazard. Besides raw materials, the design and manufacture processes are also crucial to the safety aspect of the product. Risk analysis, human factor, validation tests, and other related issues have to be taken into considerations. Another point that should be taken into consideration should be cyber-security. This is especially for device that requires operating systems which include software or a mobile application (RAMAKRISHNA et al., 2015).

Ideally, all stakeholders should cooperate to ensure the safety and effectiveness of medical devices by sharing responsibility, good communication, participation, education, and risk/cost assessment. Governments should take the lead by establishing policies, regulations, and/or standards to create healthy cooperation among stakeholders (RAMAKRISHNA et al., 2015).

Medical devices are regulated by the Brazil national health surveillance agency called Agência Nacional de Vigilância Sanitária (ANVISA), which has requirements similar to those found in the European Union (YOCK et al., 2015). Among the requirements for successful high-level primary health care it is worth mentioning: health infrastructure on a macro level (health facilities and public amenities that impact access to facilities); competent health personnel; appropriate technology. Developing countries face unique challenges that affect fulfillment of each of these (FATUNDE; BHATIA, 2012).

The Manual for Medical Device Regularization, developed by ANVISA (2017), applies the following requirements that indicate the basic controls and precautions to be observed by the manufacturer in the product design and manufacture: chemical, physical and biological properties; infection and microbial contamination; environmental and manufacturing properties; products with measuring and diagnostic function; radiation protection; requirements for medical device connected to or equipped with an electrical power source; protection against mechanical hazards; protection against the risks associated with the administration of energy and substances to the patient; protection against risks associated with self-testing and self-administration device; information supplied by the manufacturer (precautions, warnings, indication of use, instructions etc.); performance evaluation presenting, when necessary, medical device evaluation and clinical investigation.

Furthermore, the manual explains that the manufacturer is responsible for identifying, among the essential requirements, which are relevant to the product, documenting the justifications for excluding those that are not relevant. Some of the risk requirements should also be checked by the manufacturer: toxicity; flammability; biological incompatibility; residual contaminants; incompatibility with other materials, substances or gases; infection and microbial contamination; incompatibility of combination or connection with other products; instability and limitations of physical and ergonomic characteristics; sensitivity to environmental conditions; reciprocal interference with other products; impossibility of calibration and maintenance; inaccuracy or instability of measurement; inadequate radiation control; inadequate radiation protection; inadequate control of energies or administered substances; inadequate protection of energies or substances administered; intelligibility of programmable digital systems; instability of programmable digital systems; power source failures for operation; inadequate warning alarms; susceptibility to electric shocks (ANVISA, 2017). 
Medical device development is therefore a complex process that requires the careful integration of diverse disciplines, technical activities, standards, regulatory requirements, and administrative project controls. Systematic approaches to product development and maintenance are necessary to ensure a safe and effective device for the user and patient, an economical and competitive success for the manufacturer, and a reliable, cost-effective investment for the user (FRIES, 2013).

Project Management in the medical device development industries follows a more technical and formal paths, especially in the design stages of the products (SHIRLEY, 2011). In this context, among the existing approaches for developing new medical devices, diagnostics, and other technologies intended to create value for healthcare stakeholders, it is worth mentioning the following approaches.

Santos et al. (2011) developed an approach with the following phases: idea creation; identification of the customer; voice of the customer; concept generation; concept selection; preliminary design; design optimization; clinical and non-clinical studies; approval processes; launch; post-market surveillance. The identification of the customer is important to understand who will select the device and what arguments will be used to make a decision. The voice of customer is the step in which the needs are gathered. In concept selection phase, the design team is committed to a concept whose modification implies delays and additional costs. After the design of the device, the next steps are the clinical and non-clinical studies and the approval process.

El-Haik and Mekki (2008) applied the Design for Six Sigma (DFSS) approach in medical devices development, which provides managers and designers with improved visibility of the design process decision making. The phases are identify (idea creation; voice of the customer $\&$ business); characterize (concept development; preliminary design); optimize (design optimization); verify (verification and validation; launch readiness). Beyond these phases, the authors also developed mass production; consumption and disposal phases. During the mass production phase, the product will be produced and shipped to the market. Some parts or subassemblies might be produced by suppliers. During the consumption, devices are consumed by customers. This stage is really the most important to consumers, for it is the consumer who will form opinions of the design and brand name. In the disposal or phase-out phases, all products and services become obsolete, replaced by either new technologies or new methods.

Therefore, the processes related to medical device innovation are marked by systematic, structured approaches that can be learned. However, it is possible to acquire and improve the requisite knowledge and critical thinking skills on the subject (BIODESIGN, 2017). In this sense, YOCK et al. (2015), developed the Biodesign approach, which is a process of innovating medical technologies providing a comprehensive roadmap, divided in three phases: identify, invent, and implement. The purpose of the identify phase is to gather a number of unmet medical needs through observation and then screen this list down to a promising few, based on information about the key clinical, stakeholder, and market characteristics. The focus of the invent phase is to devise solutions to one or more defined needs, taking advantage of creative ideation techniques, prototyping and testing methods, and a filtering process that is based on objective risk criteria. The purpose of the implement phase is to create a multi-year plan for developing a concept into a real product that is safe and effective for patients and attractive to providers and payers. The implement phase comes toward the end of the biodesign innovation process as innovators prepare for project launch (YOCK et al., 2015). Biodesign provides a hands-on, first-hand experience more concisely captured in the phases described above (BIODESIGN, 2017). 
In sum, the main point of designing medical devices is to consider safety aspects, including the repercussions of design flaws and misuse of the device. The regulation of medical devices is also important to protect the consumer's health and safety by attempting to ensure that marketed products are effective and safe (FRIES, 2013).

\section{METHODOLOGY}

The aim of this article is to present the requirements for a PDP reference model for medical devices. Based on this objective, the methodological approach selected was the case study, which is a research strategy that aims to understand the current dynamics and combines methods of data collection (EINSENHARDT, 1989).

The case study involved documental analysis and interviews with the application of questions that sought to demonstrate the necessary requirements for health product development, such as: What were the requirements identified during the medical device development? What was the specific health activity performed during the medical device development? Was it possible to interview doctors, patients and the hospital staff? What differentiated this specific medical device project from the others sectors?

The respondents were team members of six medical devices projects, carried out at the research group in which this article is inserted. The projects selection criteria were based on the relevant innovative features of the projects developed. The general objective of the projects selected for analysis is presented in Table 1. Data collection was carried out through interviews with one team member of each project.

Table 1 - Objectives of the selected projects.

\begin{tabular}{|c|l|}
\hline Project & Objective \\
\hline A & Facilitate monitoring for diabetes patients \\
\hline B & Improve the oxygen pressure level control, as well as the accounting of work hours \\
\hline C & Measure the emolysis degree when blood is collected \\
\hline D & Prevent primary infections in the bloodstream \\
\hline E & Prevent accidents with surgical perforating-cutting materials \\
\hline F & Develop a hospital assets management system \\
\hline
\end{tabular}

Interview data of each project were qualitatively analyzed in order to elaborate the results and conclusions presented in the next sections.

\section{RESULTS}

All projects applied the Biodesign approach (YOCK et al., 2015) in order to aid with the idea generation, creation and requirements identification to find out the final solution. Biodesign was essential to acquire and improve the requisite knowledge and critical thinking skills on the subject of each project (BIODESIGN, 2017).

All participants reported that responsibility increases when developing projects for the health sector. Regulatory issues in the Biodesign Implement Phase, as Fries (2013) and Ramakrishna et al (2015) observed, are emphatic in the medical devices development.

Table 2 describes the requirements in Biodesign Implement Phase identified in each project. Note that all the projects had to follow ANVISA Manual for Medical Device Regularization 
(2017). In addition, some other sectors requirements could be applied in health sector, such as reliability and product interface with people, developed by Rozenfeld et al. (2006).

Table 2 - Requirements of the selected projects in the Biodesign Implement Phase.

\begin{tabular}{|c|c|}
\hline Project & Biodesign Implement Phase Requirements \\
\hline \multirow{2}{*}{ A } & $\begin{array}{l}\text { Convenience and compact device; suitable language for the patient and doctor through the data } \\
\text { platform; cyber-security; product interface with people; consequences of failure and safety }\end{array}$ \\
\hline & $\begin{array}{l}\text { ANVISA precautions: reciprocal interference with other products; inaccuracy or instability of } \\
\text { measurement; intelligibility of programmable digital systems; power source failures for operation }\end{array}$ \\
\hline \multirow{3}{*}{$\mathrm{B}$} & Suit the product in hospital devices; cyber-security; physical and electrical properties \\
\hline & ANATEL (National Telecommunications Agency) precautions: device interferences. \\
\hline & $\begin{array}{l}\text { ANVISA precautions: flammability, incompatibility with other materials, substances or gases; } \\
\text { sensitivity to environmental conditions; reciprocal interference with other products }\end{array}$ \\
\hline \multirow[b]{2}{*}{$\mathrm{C}$} & Convenience and compact device; validation test; product interface with people \\
\hline & $\begin{array}{l}\text { ANVISA precautions: sensitivity to environmental conditions; inaccuracy or instability of } \\
\text { measurement; residual contaminants; infection and microbial contamination }\end{array}$ \\
\hline \multirow{2}{*}{$\mathrm{D}$} & $\begin{array}{l}\text { Suit the product in hospital devices; aseptic materials; convenience and compact device; validation } \\
\text { test; product interface with people; consequences of failure and safety }\end{array}$ \\
\hline & $\begin{array}{l}\text { ANVISA precautions: sensitivity to environmental conditions; residual contaminants; infection and } \\
\text { microbial contamination; power source failures for operation }\end{array}$ \\
\hline \multirow{2}{*}{$\mathrm{E}$} & $\begin{array}{l}\text { Convenience and compact device; validation test; product interface with people; consequences of } \\
\text { failure and safety; chemical properties }\end{array}$ \\
\hline & $\begin{array}{l}\text { ANVISA precautions: sensitivity to environmental conditions; residual contaminants; infection and } \\
\text { microbial contamination }\end{array}$ \\
\hline \multirow[b]{2}{*}{$\mathrm{F}$} & Convenience and compact device; validation test; product interface with people \\
\hline & $\begin{array}{l}\text { ANVISA precautions: inaccuracy or instability of measurement; intelligibility of programmable digital } \\
\text { systems }\end{array}$ \\
\hline
\end{tabular}

However, due to government regulatory issues in Brazil, some projects did not create a multiyear plan for developing a concept into a real product that is safe and effective for patients and attractive to providers and payers, as observed by YOCK et al. (2015).

The fact of having many stakeholders, such as doctors, nurses and patients sometimes can difficult the product development because there are medical ethics issues, such as patient exposure. One point that drew attention was the fact that professional training actually affects the service quality.

\section{CONCLUSIONS}

There are many new product development approaches but few are dedicated to medical devices (SANTOS et al., 2011). Biodesign approach can assist the medical device development. However, it is still necessary to improve the research about the requirements and medical devices development in Brazil.

This article is part of an extensive research that aims to develop a specific reference model for the health sector. From the results of empirical and theoretical research, it is possible to identify the initial requirements for a PDP reference model for medical devices. It can be noticed that certain reference health centers in Brazil seek to improve the application of best project management practices for the product development in the health area. 
In this sense, firstly it is necessary to identify the relationship of requirements for the construction of a PDP reference model specific to the health area, the main focus of this work. As a consequence, for further research, the structure of the new reference model should be based on the integration of resources, scope identification, time of execution activities, budget forecast, human resources essential to the project and risk analysis. Such factors need to be considered and adapted to the reality of Brazil in order to achieve greater chances of success in health projects to contribute to a better Brazilian patients life quality.

\section{REFERENCES}

ANVISA. Resolução - RDC n ${ }^{\circ}$ 185, de 22 de outubro de 2001, 2001. Available at: <http://www.anvisa.gov.br/anvisalegis/resol/2001/185_01rdc.htm>. Accessed on May 19, 2017.

Manual para Regularização de Equipamentos Médicos, 2017. Available at: <http://portal.anvisa.gov.br/documents/33912/264673/Manual+para+regulariza\%C3\%A7\%C 3\%A3o+de+equipamentos+m\%C3\%A9dicos+na+Anvisa/ad655639-303e-471d-ac47a3cf36ef23f9 >. Accessed on May 18, 2017.

BECKER, J.; DELFMANN, P. Reference Modeling. Efficient Information Systems Design Through Reuse of Information Models. Heidelberg: Physica-Verlag, 2007. 147 p.

BIODESIGN. Biomedical Process Innovation, 2017. Available at: <http://engineering.case.edu/ebme/Research/cctrp/BioDesign>. Accessed on July 20, 2017. EISENHARDT, K. M. Building Theories from Case Study Research. The Academy of Management Review, v. 14, n. 4, 1989, p. 532-550.

EL-HAIK, B. S.; MEKKI, K. S. A Medical Device Design for Six Sigma. Canada: John Wiley \& Sons, 2008. 528 p.

FATUNDE, O.A.; BHATIA, S.K. Medical Devices and Biomaterials for the Developing World. Case Studies in Ghana and Nicaragua. New York: Springer, 2012. 112 p.

FRIES, R. Reliable Design of Medical Devices. Boca Raton: Taylor \& Francis, 2006. 504 p. Reliable Design of Medical Devices. Boca Raton: Taylor \& Francis, 2013. 501 p.

ITA. The International Trade Administration. Brazil - Medical Equipment. 2016. Available at: <https://www.export.gov/article?id=Brazil-Medical-Equipment>. Accessed on May 19, 2017.

PAIM, J. ET AL. The Brazilian health system: history, advances, and challenges. Lancet, v377, p. 1778-97, 2011.

RAMAKRISHNA, S. et al. Medical Devices. Regulations, Standards and Practices. Cambridge: Elsevier, 2015. 256 p.

ROZENFELD, H. et al. Gestão de Desenvolvimento de Produtos: uma referência para a melhoria do processo. São Paulo: Saraiva, 2006. 542 p.

RYBERG, A.B.; BÄCKRYD, R.D.; NILSSON, L. A meta-model based multidisciplinary design optimization process for automotive structures. Engineering with Computers, v31, p. 711-728, 2015.

SANTOS et al. Development of Medical Devices: Advantages of a Methodic Approach. In: Jobbágy Á. (eds) 5th European Conference of the International Federation for Medical and Biological Engineering. IFMBE Proceedings, v. 37, p. 1144-1147, 2011. 
SHIRLEY, D. Project Management for Healthcare. Boca Raton: CRC Press, 2011. 240 p.

SILVA, G.C.; KAMINSKI, P.C. Proposal of framework to managing the automotive product development process. Cogent Engineering, v4, p. 1-25, 2017.

WHO. World Health Organization. Global atlas of medical devices. 2014. 2 p. Available at: <http://www.who.int/medical_devices/countries/bra.pdf?ua=1>. Accessed on May 22, 2017.

YOCK, P.G. et al. BIODESIGN. The Process of Innovating Medical Technologies.

Cambridge: Cambridge University Press, 2015. 952 p.

ZAPIAIN, G. Top Markets Report Medical Devices. May 2016. Available at:

<http://trade.gov/topmarkets/pdf/Medical_Devices_Top_Markets_Report.pdf >. Accessed on May 20, 2017. 